\title{
Research of the Elective Course of College Art Appreciation
}

\author{
Lingjuan Wang \\ School of Architecture \\ North China University of Water Resource and Electric Power \\ Zhengzhou, China
}

\begin{abstract}
At the year of 2006, the general office of the education ministry issued the "The Guidelines of the National College Public Arts Courses", "The Art Appreciation course" is listed as one of restrictive elective courses, and it is required to be add into the teaching plan of colleges and universities, So that all the national colleges basically opened the public art appreciation course. But with the current domestic education pattern reform and update of technology, the original teaching mode cannot adapt to the new situation. So this thesis explores the teaching contents and teaching ways only from the angle of arts appreciation course, in order to find a new thought for art appreciation teaching.
\end{abstract}

Keywords-Common University Arts Appreciation Teaching Method Initiative

\section{INTRODUCTION}

Our arts education in our country has experienced a short span of twenty years from the very beginning. At the beginning, several universities have had the amateur lectures and elective courses only. But now most universities across the country have opened the elective course, even some universities formed the special organization for the art education. Up to now, its teaching scale and level was improved step by step.

Art appreciation course is an very important part of art education in colleges and universities, which is the major course to improve students' art accomplishment. The meaning of this course is not only to inherit cultural essence of art, but also to cultivate the tastes, to broaden the development space, to cultivate and improve university students' aesthetic ideal, so as to stimulate students' innovation spirit. Art appreciation teaching is an important part of public art appreciation course, and also the important way to inherit and spread culture. At present, we have two kinds of the fine arts education, one is a professional fine arts education, and the other is the ordinary art education. The former purpose is to spread the art, while the latter purpose is the "consumers of the art". And the art appreciation course is also divided into the two kinds, art major appreciation course and public art appreciation course. But the latter is covering a wide scope, which is the foundation of the art education and also the essential accomplishment for modern college students.
As the important part of art education in colleges and universities, public art appreciation course is becoming mature and perfect gradually. In 2006 year, the general office of the education ministry issued "The Guidelines of the National College Public Arts Courses". This guidelines pointed out the goal of this course teaching is: " To build up the correct aesthetic sense and elegant aesthetic taste by art appreciating, art theory learning, art activities participating and so on, to improve the humanities accomplishment; To understand and respect the cultural diversity by learning and absorbing the Chinese and foreign excellent art achievements; To develop the imaginal thinking, to cultivate the innovative spirit and practice ability; To improve the ability of beauty sensing, beauty displaying, beauty appreciating and beauty creating, so as to promote the harmonious development of physique and comprehensive in all-round way". According to the course outline of art appreciation teaching, teaching object of the public art appreciation courses are all the undergraduate students, 2 credits, 32 hours, (different universities could be slightly different according to own situation). Teaching methods to teach with the pictures show, video. During the curriculum, teachers could organize to visit the various types fine arts exhibition and conducting discussions and other visual teaching methods. The traditional teaching mode and outline already cannot adapt to the new situation due to the change of the current domestic education mode, modern science and technology continuous increasingly development, and perfection of the professional disciplines. So this thesis explores the teaching contents and teaching ways only from the angle of arts appreciation course, in order to find a new thought for art appreciation teaching.

\section{ANALYSIS OF THE COURSE CONTENT}

On the whole, the public art appreciation course has rich content and different art forms, such as painting, sculpture, craft, construction, and so on, including the Chinese and foreign arts of different. The content of the course is determined, so the key is how to teach? It is really a problem worthy to be discussed that to mainly introduce the work of art or to teach the evolution of the art history? ,. At present, except the art major students, our common college students rarely get contact with works of art in high school; basically they just learn a little related knowledge on the purpose of test. There is almost no students who specially studied the 
related knowledge of art. So there is no need to mention understanding of art and the artist. So once the teachers ask his students to appreciate the art works directly, few students can realize the artistic characteristic and connotation due to the lack of the related knowledge. So the students may lose their interests for learning arts appreciation course. Finally the students just can conduct the superficial appreciation. There is almost impossible to achieve the goal of "appreciation". If conduct the teaching from the aspect of art content, according to sequence from the Chinese landscape painting, to the Chinese figure painting, to the Chinese flowers and birds painting art, to the middle-century European Arts, to the European Arts Renaissance, to the European realism oil painting, to the European classical oil painting, to the European romanticism painting impressionism, to the European modern painting. Such sequence looks very professional, but the students who are lack of knowledge of fine arts will feel very difficult to understand and remember it as a whole package due to the scattered information. So as for the teaching of the art appreciation, it is better to combine the art history with the introduction of artists and their art works. The Content of the course should be started from the basic to intensive gradually. To teach the students the origin and progress of the artwork creation in terms of theory, art categories and characteristics, the language expression of the artwork and other related common knowledge penetrated into art appreciation. So in this way, all the students can easily accept on the information according to their previous knowledge and experience.

\section{ANALYSIS OF THE TEACHING METHOD}

During the teaching period, teachers should give students enough space for imagination without any repeating of what book says and teachers should teach students how to sense the tradition from the artworks. It is better to introduce the teachers' realization from the art works appreciation than directly to teach students how to conduct the art appreciation. The meaning of the teaching is to let students learn something not on a specific purpose. According to the principle of the art development and social culture and technology, teachers need to introduce the origin of the art, the relationship of productivity and beauty. To lead students to understand the relationship between the art and society, art and technology, taking the students lack of knowledge as breakthrough point. The teaching covers from the change of the artworks' raw materials to the change of the painting forms and methods, such as the emergence of the paper, invention of the oil paints, the development of optical technology, the invention of the camera and so on, all these technology innovation to promote the development of the fine arts.

Following is our ideas about the teaching method: 1 . to combine the artist with the times background of the art works. When introducing one of the art works, it is better to introduce from the background, cultural trends, art characteristics and also the artist himself experience. The artwork is the expression of the artist's experience and cultivating. The artworks design, content, tunes, forms, even raw materials are all related with the artist experience and times background. The feature of the artworks is also expressed by all the above aspects. So during the teaching, it is better to explore the artworks background and features on purpose to cultivate the students' aesthetic sense. 2. To combine the teaching content with the local resources. Except for the lessons, teachers can organize the visit of local artworks to strengthen the students' sense of the arts. Such as after the teaching on lessons, teachers can lead his students to visit the museum and ask them for introduction. The real visit can help students to understand the artworks background and arts value easily, to fully use the resources from the library, museum, exhibition and so on. Then the teachers need to lead students to sense the beauty and found the arts elements around. 3. To combine the appreciation with the discussion. The artworks appreciation is the recreation of arts. From the different sense of different individual artworks, students can easily broaden his views and form the correct sense of beauty. The understanding and realizing of the artworks can help students to cultivate language expressing ability and meanwhile push students for further thinking. Under the teacher's excitation and induction, the student can make a think during the discussion. During their thinking and solving of the questions, students can experience as the artist's thinking process. This experience can make students feel happy; this happiness will be the power for them to keep exploring. One's success generally is from his pursuit of the happiness of thinking and solving questions. On the contrary, if teachers implant their ideas to students, the students cannot feel the happiness as individual thinking and solving the questions, and then they will lose their interests on learning. After the discussion on lesion, the teachers can ask students to write a small conclusion. The purpose of the conclusion is to check the students learning and also to know the results of teachers' teaching. And teachers also can prepare and adjust the teaching design according to the conclusion.

\section{The ANAlysis of The StUdents' InITIATIVE}

The best way to achieve the good teaching effects is to give full display to the students' learning Initiative. The interest of students is decisive for the students' study and the teachers' teaching. Firstly, the students' interest is the premise to enhance the teaching effects. The students definitely do not lack of interests in art who have take the art appreciation as the elective course. It is a good starts, teachers should begin with the interests of students, to create a scene, to stimulate their interests, so as to create a certain psychological atmosphere. Such as on the first lesson, teachers can start from the point of "how the artworks to be given birth" such a fascinating topic, then to let the students feel the meaning and connotation of the artworks from the birth of artworks, to unravel the mystery of artworks, to shorten the distance between the art and students. To let students totally understand the close relationship between artists and their artworks, then they will notice that the artworks are created by people and we are the part of the art recreation. They will learn to appreciate the artworks from themselves and respect their own aesthetic feeling and aesthetic experience. Secondly, to optimize the teaching atmosphere in class. Influenced by the traditional teaching 
concept, students dare not answer questions in class and also don't want to answer question. If the students dare not to raise questions in class, their innovation consciousness won't to be get promoted, in this way it will be very difficult to let the students to display their strong personality. Only the lesson with question raising, questions explaining and questions solving, students' subjectivity can be totally displayed. The purpose of the teachers' questions is not only to let students grasp the knowledge of artworks, but also to let the students appreciate and analysis the artworks by using their own knowledge. Such as when appreciating the abstract artworks of the modern artists such as Picasso, Dali, the expressionism, the abstract expressionism, the cubism and so on, most students cannot understand well and they will feel the artwork is not meaningful and question the value of artwork. Then we can organize students to discuss, then guiding students to analyze the works of art from their studied knowledge, from the artistic language of point, line, overall, shape, light and shade, color, texture and other artistic elements.

Then to teach the student to fully grasp the artwork by understanding the background of the artist, the artistic creation and other related factors. And then to let the students to find out the related modern abstract symbols from their daily life, then ask them to find the abstract symbols in sculpture, clothing, packaging, construction, interior decoration and other fields of application of the image, so that the students can get a whole of perceptual knowledge of modern art, and then organize the students to observe and discuss through the image, video, works to have a further understanding of abstract art, so as to eliminate their prejudice against the abstract paintings.

To let students achieve smoothly the process of "questions to thinking to familiar, to understand" is very helpful for students to grasp and understand the knowledge, so that can really help students to understand the work. Discussing teaching methods not only help students to have a active mood and active thinking, but also enhance their memory and efficiency for study. To let the students to participate in the teaching process can make the students from to passively accept knowledge into to actively seek knowledge. In this way the students will be cultivated to analyze and solve problems by themselves. Finally, teachers need to let the students themselves to find their favorite artworks or artists during the courseware making process. During the analysis of their interested artists or artworks, they will learn to find information, learn from the artist's personal experiences and background to analyze the unique artistic style, artistic value of artworks. After the finishing of the teaching demonstration courseware, we need to do the trail lecture to found the shortcomings and then to improve it. During the process of courseware making, the students are cultivated of the practical ability. The students also are cultivated the ability of thinking, literature searching, operating by collecting the data. Their interests also are enhanced during this process. From the study of the art appreciation, most of the students do not have a very clear acknowledge of this course, but they feel it is useful for their study and life. The common problem for each student's study of the painting is how to appreciate a painting especially the abstract style painting. It is reflected a kind of problem that most of the students lack of the knowledge of the art theory and appreciation experience, although they all have interests. The key for appreciating a painting is to get the knowledge of the artworks historical background, the cultural background and even the artist and their creating thoughts background. If the students just appreciate the painting artworks superficially, they will feel it is very mysterious and hard to understand. So the relationship between artworks and real life will be separated. During the study of art appreciation course, we noticed that the simple study of art appreciation makes students losing their interests of further study. Only to connect the study with the related knowledge and social life, their passion of study could be stimulated. The college students have stronger logistic thinking ability and divergent thinking ability, So the task of teachers is to find a method to teaching their students correct thinking method and attitude to solving the problem. The goal of the art appreciation course is to teach students to appreciate the artworks the world by their own eyes.

\section{CONCLUSION}

Along with the enhancing of the art education status and functions, presently most of the universities have opened the art appreciation courses. Its meaning is not only the teaching on class, but also it can help the students to sense and find beauty in the life. The art's diversity comes from the different artworks of different sociability and reality from different periods and different regions and also the restrictions of the political, economic, religion, culture, science and technology. The development of art is the microcosm of the human history development and also is kind of reflection of human spiritual life and material life. The Art teaching function is not only for identify and appreciate, but also for communication as the final purpose. The art appreciation is a dialogue or lesson or development for enhancing the people's cognitive ability and quality. In addition, when the students meet problem for choosing a career, he will has an urgent desire for all aspects of different knowledge. Along with the development of sincere and technology and the development of society, our understanding of beauty is also enhancing with the developments. So the artworks appreciation course also need to be developed in practice and to be constantly adapted to the new needs and the new environment.

\section{REFERENCES}

[1] Zhang Jinfeng. The Study of Common College Art Appreciation Course[J].Da Zhong Wen Yi, 2009,19: 178

[2] Ouyang Qiming. The Discussion of Art Appreciation Course Reform[J].Capital Normal University Journal(The Social Science Version), 2008(Supplement):8-10 